Vulnerability of lakes to fish invasion impacts

\title{
Assessing vulnerability of New Zealand lakes to loss of conservation value from invasive fish impacts
}

\author{
KEVIN J COLLIER ${ }^{\mathrm{a},{ }^{*},}$, JOHN R LEATHWICK ${ }^{\mathrm{b}}$ and DAVID K ROWE ${ }^{\mathrm{c}}$ \\ ${ }^{a}$ Environmental Research Institute, The University of Waikato, Hamilton, New Zealand \\ ${ }^{\mathrm{b}}$ Silverdale Road, Hamilton, New Zealand \\ ${ }^{c}$ National Institute of Water and Atmospheric Research, Hamilton, New Zealand
}

*Correspondence to: Kevin Collier, Environmental Research Institute, The University of Waikato, Private Bag 3015, Hamilton 3240, New Zealand

\section{ABSTRACT}

1. We linked predictions of invasion risk for seven non-indigenous fish species, ecological impact scores for individual species, and lake conservation rankings to develop Invasion Risk Impact (IRI) and Lake Vulnerability (LV) indices that help identify New Zealand lakes most at risk of loss of conservation value from potential multi-species invasions.

2. Species-specific $I R I$ scores (the product of predicted invasion risk and species impact) highlighted Eurasian perch (Perca fluviatilis) and the brown bullhead (Ameiurus nebulosus), as the species most likely to spread and cause ecological harm in lakes. For 3,431 lakes $>1$ ha throughout New Zealand, total IRI tended to be highest for lowland riverine and dune lakes most of which are already colonised by multiple invasive fish species.

3. The $L V$ index indicated lakes most at risk of loss of conservation value from invasive fish impacts were predominantly (i) in the northern half of the North Island where several uncommon lake types occur, and (ii) along the west coast of the South Island where conservation value is often greater, largely due to low catchment modification.

4. The $I R I$ and $L V$ indices can be used to assist with prioritising surveillance monitoring, advocacy, and response planning targeted at preventing the establishment of invasive fish in moderate-to-high value lakes most susceptible to ecological impacts. Both indices can be adapted to accommodate alternative impact and conservation scoring systems, providing a flexible tool for local- and national-scale assessments of lake vulnerability to fish invasion impacts.

KEY WORDS: lake; introduction; modelling; fish, alien species

\section{Introduction}

Preventing or slowing the spread of invasive species is a cornerstone strategy for many environmental management agencies charged with conserving indigenous biodiversity and ecosystem health (Vander Zanden and Olden, 2008). For established invasive species that have not yet occupied their potential geographic range, a key component of such strategies involves 
Vulnerability of lakes to fish invasion impacts

identifying locations where environmental conditions would enable their proliferation, and prioritising sites for monitoring and surveillance so that scare resources can be directed to areas of highest concern (Mercado-Silva et al., 2006; van der Veer and Nentwig, 2015). Previous studies have highlighted the value of quantitative modelling approaches for predicting sites prone to ecological damage from invasive fish, thereby assisting the effective targeting of prevention efforts (Kolar and Lodge, 2002). Several studies have also developed scoring systems for assessing impacts of, and risks from, alien fish invasion (e.g., Clavero, 2011; Copp et al., 2009; van der Veer and Nentwig, 2015), with Britton et al. (2011) incorporating ecological and socioeconomic risk, along with impacts and costs of management actions, in a scoring framework for managing introduced fishes in the United Kingdom.

Invasive species have become widespread in lentic waterbodies in many parts of the world where they have dispersed rapidly through connected freshwater networks, and spread further through accidental or intentional human release (Strayer, 2010). Indeed, Dudgeon et al. (2006) rated invasive species as one of the five key threats to freshwater biodiversity globally, and their spread is predicted to become an increasingly significant factor affecting the ecological health of lakes and ponds in the years to come, particularly with the prospect of a warming climate (Brönmark and Hansson, 2002; Rahel and Olden, 2008). Continuing spread of invasive fish among lakes can lead to biotic homogenisation (Rooney et al., 2007), heightening losses of indigenous biodiversity. Additionally, non-native fish can have high trophic overlap with or prey on native species with cascading implications for aquatic food webs (Morgan et al. 2002; Smith and Lester, 2007; Matsuzaki et al., 2011; Córdova-Tapia et al., 2015); they can also alter internal nutrient cycling thereby increasing the primary productivity of waterbodies in which they proliferate (Villéger et al., 2012). Generally, impacts of invasive fish in New Zealand waterbodies occur through the combined effects of nutrient excretion, bioturbation, predation, loss of macrophytes, food-web modification and inter-specific aggression (see Collier and Grainger, 2015 for review).

New Zealand is considered one of six global hotspots for fish introductions with non-indigenous fish comprising around one-quarter of all freshwater fish species in the country (Leprieur et al., 2008). All but five of New Zealand's native freshwater fish species are endemic (McDowall, 2000). Most are species of small size whose numbers have reduced significantly due to loss of connectivity and increased catchment land-use pressures, making the remaining populations vulnerable to the added effects of invasive species. Endemic pelagic piscivores are naturally absent from New Zealand waters, leading to the potential for development of large populations of invasive species. Furthermore, as introduced species richness often exceeds native fish diversity in some waterbodies, with 5-6 introduced fish species found in some lakes (Rowe, 2007; Drake et al., 2010), multiple invasive species have the potential to heighten interactions with native fish communities. Reinforcing the importance of multi-species impacts, Rowe (2007) reported that the relationship between water clarity and lake depth was dependent on the number of invasive fish species established in a waterbody.

As a contribution to the conceptual framework proposed by Vander Zanden and Olden (2008) for assessing site vulnerability to invasive species in a landscape comprised of multiple lakes, the present study aimed to develop and apply tools to assist with identifying New Zealand lakes most at risk of adverse effects from the potential establishment of multiple invasive fish species. Specifically, our objectives were to (i) develop indices that express vulnerability of lakes by linking predictive models of invasive fish establishment with existing management frameworks for assessing species' invasion risks and for ranking lake conservation value, and (ii) apply these indices to lakes across New Zealand to highlight areas of potential impact from invasion by multiple invasive fish species. 
Vulnerability of lakes to fish invasion impacts

We are not aware of existing invasive species management frameworks that integrate model predictions of potential invasive fish spread with multi-species impacts and ecosystem values at risk of being compromised. Accordingly, we report on the development of new indices that express Invasion Risk Impact (IRI) and Lake Vulnerability (LV) to map adverse effects for seven non-salmonid fish that have invaded freshwater ecosystems across New Zealand: the brown bullhead (Ameiurus nebulosus; referred to hereafter as catfish), western mosquitofish (Gambusia affinis referred to hereafter as gambusia), goldfish (Carassius auratus), common carp (Cyprinus carpio), Eurasian perch (Perca fluviatilis), rudd (Scardinius erythrophthalmus), and tench (Tinca tinca). We apply these indices across 3,431 mapped New Zealand lakes and present a framework to illustrate how these indices can be used to identify moderate-high value lakes most susceptible to loss of conversation value from invasive fish impacts.

\section{METHODS}

\section{Invasion risk modelling}

Presence-absence records for the seven invasive species, collected over the period 1980-2014, were extracted from the Lake Ecosystem Restoration New Zealand (LERNZ) database (http://lernzdb.its.waikato.ac.nz/) and the New Zealand Freshwater Fish Database (NZFFD-McDowall and Richardson, 1983; https://nzffdms.niwa.co.nz). This yielded 1,469 individual sampling events from 470 lakes. Physical predictor variables were drawn from a classification of all New Zealand lakes with areas $>1$ ha (Snelder, 2006), with additional variables drawn from a more recent distributional study of lake macrophytes (Compton et al., 2012). These records and variables were used to generate a predicted invasion risk (PIR; range $0-1$ ) score for the seven non-native fish species listed above in all New Zealand lakes $>1$ ha for use in subsequent calculation of impact and vulnerability indices (see below).

The physical predictor variables included descriptions of (i) lake size, (ii) landscape-scale factors influencing conditions within each lake and its surrounding catchment (e.g., climate, mean slope, percentage areal coverage by peat or different land uses), (iii) connectivity with adjacent waterbodies (number of river segments occurring within a $15 \mathrm{~m}$ buffer of the perimeter of each lake, proportional cover of other lakes within a $100 \mathrm{~km}$ zone around each lake), and (iv) human population (mean density within $100 \mathrm{~km}$ of the lake perimeter, proportional cover of urban environments, number of roads within the immediate vicinity, shortest distance from the perimeter of each lake to its nearest state highway) (see Table S1). In addition, a binary spatial variable was constructed for each invasive fish species indicating whether it had been recorded elsewhere in the broader river catchment within which each lake was located; this variable enabled assessment of the potential for spread by each species, conditional on their introduction within a river system.

All species distribution models were constructed using boosted regression trees (BRT), an ensemble method that combines a large number of simple tree-based models (Friedman 2001, 2002) to form a robust, multiple-regression type model. All models were fitted using scripts developed in $\mathrm{R}$ (Elith et al., 2008) using version 2.1 of the ' $\mathrm{gbm}$ ' library (Ridgeway, 2015). A ten-fold cross-validation process designed to maximise performance when predicting to withheld sites was used to determine the optimal level of complexity for each model. The Area Under the Curve statistic (AUC; Hanley and McNeil, 1982) was used as an indicator of model performance, and reflects the degree to which predicted values discriminate between presences and absences in the training dataset. Values 
Vulnerability of lakes to fish invasion impacts

greater than 0.8 are generally considered to indicate a satisfactory level of model discrimination (Leathwick et al., 2008).

An initial set of predictions was made for the seven species in all lakes $>1$ ha, for which environmental data were available, using models containing predictor variables describing just the physical environment of each lake and human population densities in its surrounds. A second set of predictions was made for the three species for which spatial variables describing species occurrences in the surrounding river catchments were included as significant model terms. These models indicate the likely future probability of species occurring in individual lakes, should they be introduced into the broader river catchment within which each lake is located. Further details on the modelling approach are provided in Leathwick et al. (in press).

\section{Quantifying invasive fish impact}

Ecological impact scores (EIS) were derived from the Fish Risk Assessment Model (FRAM) published by Rowe and Wilding (2012) for New Zealand non-native fish as follows: catfish - 26, gambusia - 28, goldfish -17 , common carp -32 , perch -31 , rudd -22 and tench -17 . These scores were derived by Rowe and Wilding (2012) from the responses of three New Zealand freshwater fish specialists to 35 questions on reported species-specific characteristics and impacts in New Zealand and other countries. It considers feeding and competition impacts, reproductive rate, dispersal mechanisms, invasive relatives, special quarantine requirements, and undesirable traits (for the full list of questions see Table S2). The impacts assessed effects on lake ecosystems, indigenous biodiversity, aquatic habitats and fisheries, with scores weighted to reflect the perceived relative importance of impacts for New Zealand lakes (e.g., piscivory was weighted higher than omnivory for biodiversity impacts). Consensus assessments were obtained with "yes", "no", and "unsure" response options. Uncertainty was dealt with by recording the highest score possible for an "unsure" response to a question. This approach will have over-estimated overall risk, but was adopted as a precautionary measure. In the face of such uncertainty, it assumes maximum risk until reliable data indicate otherwise. Although the approach used by Rowe and Wilding (2012) did not fully quantify uncertainties associated with responses (e.g., IPCC 2005), as used to improve the FISK method for assessing invasive fish impact (Copp et al. 2009), it was applied in the present study because it represents the only invasive fish impact scoring system developed specifically for New Zealand conditions.

An invasion risk $\mathrm{x}$ impact $(I R I)$ score was derived for each species from the product of $E I S$ and $P I R$. Species $I R I$ scores were standardised to the range $0-1$, and an overall $I R I$ score represented the sum of non-standardised values for all focal species (Equation 1 ).

Invasion Risk Impact $(I R I)=\sum P I R_{i} * E I S_{i}$

(Equation 1)

Where: $P I R_{\mathrm{i}}$ represents predicted invasion risks for the seven species and $E I S_{\mathrm{i}}$ indicates their ecological impact scores (from Rowe and Wilding, 2012), with the sum standardised into the range $0-1$.

\section{Conservation prioritisation of lakes}

National conservation ranks for New Zealand lakes from Leathwick et al. (2010) were used in the analyses described here to represent conservation value (CV). These ranks were calculated using the spatial conservation prioritisation software Zonation (Moilanen et al., 2005, 2009), which ordered sites according to their ability to contribute to the representation of a full range of biodiversity features, in this case lake types. Given a lack of comprehensive biological data, an 
Vulnerability of lakes to fish invasion impacts

environmental classification was used to discriminate different lake types, using a similar set of classification variables (lake- and catchment-scale factors) as those used for our fish prediction models (Snelder, 2006). Rankings took account of estimated lake condition calculated from natural catchment vegetation cover, land-use pressure and urbanisation in each lake catchment. Ranks were not available for 164 lakes, these either being too small to be represented by the gridded raster layers used in ranking, or because they were ranked separately as part of the assessment for wetlands in which they occur. Rank values indicate the proportion of the total area of all New Zealand lakes that would be included within the priority set at any given level of protection or management. For example, protecting all lakes with scores in the range $0-0.1$ would protect $10 \%$ of all lakes by area, extending protection to lakes with scores in the range $0.1-0.2$ would protect $20 \%$ of all lakes, and so on.

\section{Identifying lake vulnerability}

An overall Lake Vulnerability $(L V)$ index combining information about invasion risk, expected fish species impact, and conservation value was calculated for each lake as:

$$
L V=(1-C V) * I R I
$$

(Equation 2)

Where: $C V$ represents its conservation rank, with values inverted so that higher ranked sites have higher scores, and $I R I$ represents the lake-specific invasion risk impact from Equation 1.

Highest $L V$ scores represent those lakes where the probability of invasion and ecological impact are high for the seven non-native fish species, and where conservation rankings are highest based on the biologically-relevant environmental classification groupings described above. For visual representation purposes the $I R I$ and $L V$ were split into three rounded natural breaks using ArcGIS 10.3; for $I R I$ these were $<0.1,0.1-0.4$ and $>0.4$ and for $L V$ these were $\leq 0.1,>0.1-0.25$ and $>0.25$. We use case-study examples in northern small dune $\left(0.8-1.6 \mathrm{~km}^{2}\right)$ and shallow

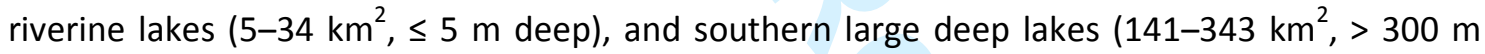
deep) to illustrate our results.

\section{RESULTS}

\section{Invasion risk and impact}

Predictive models of fish distributions describing probability of establishment (i.e. predicted invasion risk, $P I R$ ) for all seven species using environmental data from currently recorded locations had high predictive ability (AUC $>0.8$ - Table 1 ) when based on a mix of environmental, human population and spatial predictors. Models predicting invasive fish occurrence in all lakes with extents $>1$ ha, based on environmental and human variables and assuming presence in the catchment for three of the species, indicated invasion risk was highest for perch and catfish, with median probabilities of establishment of 0.33 and 0.30 , respectively (see Table 1 ).

IRI scores for the seven invasive fish species also highlighted perch and catfish as the species most likely to cause ecological harm generally across lakes (Table 2A). These species, along with rudd, had $95^{\text {th }}$-percentile $I R I$ scores $>0.5$. Common carp had the lowest $95^{\text {th }}$-percentile species $I R I$ score reflecting limited predicted establishment beyond its current range (see Leathwick et al., in press for further discussion). Low median scores for gambusia, and wider $5^{\text {th }}-95^{\text {th }}$ percentile range compared to carp ( 0.178 of 0.073 for carp; Table $2 A)$, reflect the predicted restriction of large impacts of gambusia to shallow, warmer lakes and the absence of established source populations for both 
Vulnerability of lakes to fish invasion impacts

species from the South Island. IRI scores for all species highlighted greatest invasion risk impacts in the upper and lower North Island and scattered lakes along the east coasts of both islands (Figure 1A). The high IRI score for catfish relative to gambusia and common carp is because the latter two species have a low probability of spreading to many lowland lakes in the coastal South Island where they are currently absent.

Numbers of invasive species currently present in lakes that have been sampled ranged from 1 to 6 , with numbers generally higher at sites with $I R I$ values $>0.5$ and spanning the full range of conservation ranks (Figure 2A). The 10 lakes occurring at the top right of the plots were all northern riverine or dune lakes in which multiple invasive species are already present, comprising various combinations of goldfish, common carp, catfish and gambusia (Figures 2B-E). Catfish, carp, gambusia, rudd and tench were typically recorded at sites with $\mid R I>0.4$. Goldfish were present in lakes covering a wide range of $I R I$ scores (Figure $2 C$ ), reflecting in part their relatively low EIS in the FRAM (Rowe and Wilding, 2012). Perch, which had a high EIS, tended to occur mostly in lakes with $\mid R I<0.4$ and it was typically the only invasive species recorded (Figures $2 \mathrm{~A}$ and $\mathrm{F}$ ).

\section{Vulnerability of lakes to invasive fish impacts}

When information about conservation rank was combined with predictions of invasion risk for all species, as in Equation 2, overall median lake vulnerability to invasive fish impacts was 0.11 (Table 2B). Vulnerability to loss of lake conservation value nationally was highest for impacts from perch followed by catfish, with both species having median $L V$ values $>0.15\left(95^{\text {th }}\right.$-percentiles $=0.54$ and 0.37 , respectively), followed by rudd and goldfish $\left(95^{\text {th }}\right.$-percentiles $=0.26$ and 0.21 , respectively). Mapping of $L V$ at the national scale revealed that the northern half of the North Island had many lakes with predicted overall vulnerability scores $>0.25$, while other vulnerable lakes are scattered around coastal locations of both main islands (Figure 1B). The high intensity of moderately vulnerable (0.1-0.25) lakes along the west coast of the South Island partly reflects high conservation ranks in this relatively undeveloped part of the country (Figure 1B). Notably, lake vulnerability to impacts by catfish and perch was predicted to be high in those lakes (Figure 3 ), in part because these species already occur in that region.

Conservation rankings for the case-study coastal dune lakes varied substantially (Table 3), partly reflecting catchment pressures and lake area. $I R I$ scores for those lakes were similar due largely to a high probability of invasion by perch $(0.58-0.80)$, which had amongst the highest EIS, followed by rudd (0.35-0.58) and catfish (0.30-0.33). Taking account of the combined effect of conservation rank, invasion risk and species ecological impact, the $L V$ index indicated low vulnerability for the lowest ranked Lake Kanono, and highest vulnerability for Lake Humuhumu (Table 3) which had the highest probability of invasion by gambusia $(P I R=0.55)$. All three focal riverine lakes had very high overall vulnerability to invasive fish impacts, reflecting the combination of moderate-to-high invasion risk across a range of species, and high conservation rank because of the rare lake type nationally irrespective of ecological condition (Table 3). Several fish species with ecological impact scores $>25$ contributed to the high LV. PIR values were $>0.6$ for catfish, goldfish, common carp and gambusia, and also for rudd with the exception of Waikere, while perch invasion risk was between 0.39 and 0.49 . In contrast, the large deep lakes in the South Island had low vulnerability $(<0.15)$ to invasive fish impacts on conservation status (Table 3 ). This result reflects the low PIR for most species in those lakes ( $<0.1$ for common carp, goldfish, gambusia, tench) because of their isolation from population centres and cooler water temperatures. Highest invasion risks were for catfish (0.30-0.65), followed by perch (0.26-0.38) and rudd (0.18-0.23). 
Vulnerability of lakes to fish invasion impacts

\section{DISCUSSION}

The need to allocate scarce resources effectively and efficiently to optimise biodiversity conservation outcomes is a key challenge for environmental managers. This imperative requires the development of tools that assist with prioritising key locations for management, including facilitating a more proactive approach towards prevention and eradication of invasive species (Kolar and Lodge, 2002; Vander Zanden and Olden, 2008; Havel et al., 2015). Modelled estimates of species invasion risk coupled with information on waterbody prioritisation provide an important focus for targeting surveillance and protection efforts (Compton et al., 2012), particularly in lakes at risk of invasion by multiple species that may have additive, synergistic or even antagonistic impacts on communities and ecosystems (Rowe 2007; Havel et al., 2015; Collier et al., 2015). Available fish distribution records indicate that all sites identified as having high vulnerability to invasive species impacts in the present study are already colonised by two or more species. Riverine and dune lakes appear to be particularly vulnerable because of their smaller size, lowland setting, relative ease of road access, and, for riverine lakes at least, high connectivity with adjacent rivers and wetlands. At present, perch occur as the only invasive species in many lakes, leading to reduced overall invasion risk impact; however, this aggressive predator can still cause significant ecological damage even in the absence of other invasive species (Collier and Grainger, 2015).

The coupling of probabilistic models of invasion risk for seven introduced fish with existing species' ecological impact scores and lake conservation rankings highlights vulnerable locations where biosurveillance and invasion response planning could be prioritised. In particular, our work identifies potential risks posed to conservation status in New Zealand's western South Island lakes, notably from impacts of catfish and perch invasion. Similarly, it identifies scattered locations in the North Island where there is a potentially high risk of major impacts on lake conservation values from a range of warm-water fish species. The value of such analyses is highlighted by the recent discovery of catfish in Lake Rotoma, a central North Island volcanic lake, where invasion risk modelling indicated a high probability of potential occurrence $(P I R=0.821)$, similar to the already-established goldfish (0.918) and gambusia (0.865). The ability of managers to identify locations that are vulnerable to invasion is central to limiting impacts of recently-established species (Mercado-Silva et al., 2006) or preventing future invasions (so-called "smart prevention"; Vander Zanden and Olden, 2008).

Analysis of the relationship between relative conservation rank and $I R I$ provided a framework for identifying priority lakes for monitoring. The shaded rectangle in Figure 4 highlights many lakes of moderate-to-high conservation rank which have a moderate probability of adverse environmental impacts from alien fish invasion, in which either no monitoring has yet been carried out or invasive fish have not yet been recorded. We propose that these lakes should be considered priorities for surveillance, although clearly other unpredictable factors, including human-mediated spread, are also at play, as evidenced by records of perch and goldfish in lakes with low IRI scores. For example, in addition to human population density, Copp et al. (2010) highlighted the importance of fish imports, garden centre density and fish farm density as predictors of propagule pressure for a range of non-native fish species, including goldfish, in England. In addition, the management of sports fish species, such as perch in New Zealand, is likely to have also resulted in widespread introduction to various lakes in the past.

The addition of conservation rank to develop an overall index of lake vulnerability provides an added layer of information with which to prioritise monitoring actions, based on the assumption that higher ranking lakes are more vulnerable to loss of ecological value than more degraded lakes and/or larger or more common lake types. Assessment of conservation value in the present study 
Vulnerability of lakes to fish invasion impacts

used an existing ranking system based on biologically-relevant environmental variables to identify a range of lake types, and by inference biological community types, present across New Zealand lakes. This environmentally-driven approach to conservation assessment differs from other studies that have accounted directly for impacts on native biodiversity based on distributional overlap of native fish likely to be affected by invasive species (e.g., Mercado-Silva et al., 2006), and enables broadscale assessment to be made across all lakes for which little biological data exist.

Although median vulnerability across all New Zealand lakes $>1$ ha was low ( $L V=0.11$ overall and < 0.20 for individual species; Table 2), the spread of species values indicated that a significant number of lakes (upper $5 \%$ of the 3,431 lakes evaluated or 172 lakes) have high vulnerability ( $L V \geq 0.54$ ) to impacts from perch, and moderate vulnerability to impacts from catfish ( $L V>0.36$ ), providing important information for developing species-specific monitoring plans. Furthermore, the case study examples underscore the important influence of conservation rank, as a representation of the suite of ecological values potentially at risk of compromise from invasive species impacts, in determining lake vulnerability (e.g., for coastal small dune lakes; Table 3), and the significant impact of alreadyestablished multi-species invasions in shallow riverine lakes which represent a rare lake type in New Zealand generally. In contrast, the focal large deep lakes in the South Island were less vulnerable to invasive species impacts on conservation value partly because of their generally lower risks of invasion by multiple species, and partly because of their larger area and the number of examples that are available to provide representation of this lake type.

To have an ecological impact, a species must first be introduced and establish in sufficient numbers to influence key lakes processes (e.g., predation on species mediating trophic exchange; Vander Zanden et al., 2004), and this must occur over a sufficient scale to induce ecological change. Risks of invasive species impacts are most severe in shallow lakes where they have been associated with regime shifts (e.g. Schallenberg and Sorrell, 2009; Havel et al., 2015). The spatial predictions of establishment in the present study did not account for lake depth or trophic state due to lack of data across all New Zealand lakes, highlighting a need for post-assessment evaluation of site-specific autecological factors likely to influence the success of particular invasive species. Lakebed morphology is also likely to be important as some areas within lakes (e.g. shallow littoral zones) are likely to be more suitable than deeper water habitats for various life history stages. Knowledge of site-specific and within-lake variation in habitat suitability for different invasive species will also provide important guidance for targeted monitoring activities based on knowledge of species invasion risk. Lake-specific data on the presence/absence of rare or threatened indigenous species that may be affected by non-indigenous fish invasion will also help broader invasive species impact assessments for particular locations.

Although our analysis did not include small ponds or impoundments $(<1$ ha in area) because comprehensive GIS layers were not available, inclusion of natural and artificial small waterbodies, especially those with high visual exposure (Johnson et al., 2008; Kizuka et al., 2014), can be expected to improve invasion risk predictions in the future as this information is acquired. Furthermore, as with other studies forecasting invasion potential (e.g., Mercado-Silva et al., 2006), our analyses represent a static scenario that does not account for future shifts in land-use, hydrological resource use or climate, as highlighted by Vander Zanden and Olden (2008). In particular, a warming climate is likely to lead to shifts in invasive species distributions and abundances in lakes, with unpredictable impacts on ecological processes and species interactions (Rahel and Olden, 2008). Indeed, Tricarico (2016) highlighted the need for understanding behavioural responses of invasive species to global warming to help unravel synergistic interactions between climate change and biological invasion. Responses of individual lakes to climate change are likely to vary dependent on a range of factors 
Vulnerability of lakes to fish invasion impacts

including size, depth, altitude, latitude and hydrological pathways of inflows, making predictions of invasive species responses across all lakes complex. For the indices proposed in the present study, impacts of future climate change will need to be considered separately taking account specific lake attributes and values.

The $I R I$ and $L V$ help quantify key stages in the conceptual framework proposed by Vander Zanden and Olden (2008) for assessing site vulnerability to invasive species in a landscape comprised of multiple lakes. However, this framework does not identify economic costs of species invasions (cf van der Veer and Nentwig, 2015; Walsh et al., 2016), and nor does it include the impacts and costs of management actions (cf Britton et al. 2011) or uncertainties associated with assignment of impact scores and modelling predictions where uncertainties are likely to be greater at finer spatial scales (cf Copp et al., 2009; Papes et al., 2011). Nevertheless, scores for each species can be evaluated individually to identify relative impacts on conservation value, enabling prioritisation of species for more in-depth analysis of potential invasion and impact, and providing an important focus for the development of species-specific response plans to potential incursions. For example, in relation to the recent discovery of catfish in the volcanic lake mentioned above, our modelling predicted that the invasive fish species next most likely to impact that lake is rudd $(I R I=0.66)$. Surveillance monitoring for this lake might therefore be targeted towards methods and habitats appropriate for detecting that species. However, it should be noted that similar modelling based on threats to fisheries and/or social values (as opposed to conservation values) could indicate that other species pose a similar if not greater threat to these lakes than rudd.

Broadscale environmental data layers for lakes and connected river networks, and high predictive ability of species' invasion risk incorporating human population and spatial factors, provide powerful tools for exploring lake vulnerability over multiple scales across the landscape (see also Papes et al., 2011). The indices developed in the present study coupled to geographic information system platforms can be used alongside other information, including climate change scenarios, knowledge of species biology and abundance-impact relationships (Latzka et al., 2016), to help prioritise sites and activities for particular geographic contexts as part of spatial conservation planning. Furthermore, the indices developed can be adapted to accommodate alternative systems for deriving appropriately scaled impact and conservation scores, providing a flexible tool for local- and national-scale assessments of lake vulnerability to fish invasion impacts.

\section{ACKNOWLEDGEMENTS}

We thank Glen Stichbury for producing the maps, and Brendan Hicks, Nicholas Ling and Mary deWinton for valuable discussions on species invasion risk. Thomas Wilding contributed to the initial development of the Fish Risk Assessment Model adapted for use in the present study. We appreciate the helpful comments of two anonymous reviewers. The study was funded by Ministry of Business, Innovation and Employment contract UOWX0505.

\section{SUPPORTING INFORMATION}

Table S1 Predictor variables used to model invasion risk of seven fish species

Table S2 Fish Risk Assessment Model (FRAM) questions used to determine ecological impact scores

http://mc.manuscriptcentral.com/aqc 
Vulnerability of lakes to fish invasion impacts

\section{REFERENCES}

Britton JR, Copp GH, Brazier M, Davies GD. 2011. A modular assessment tool for managing introduced fishes according to risks of species and their populations, and impacts of management actions. Biological Invasions 13: 2847-2860.

Brönmark C, Hansson L-A. 2002. Environmental issues in lakes and ponds: current state and perspectives. Environmental Conservation 29: 290-306.

Clavero M. 2011. Assessing the risk of freshwater fish introductions into the Iberian Peninsula. Freshwater Biology 56: 2145-2155.

Collier KJ, Grainger NPJ. eds. 2015. New Zealand Invasive Fish Management Handbook. Lake Ecosystem Restoration New Zealand (LERNZ; The University of Waikato) and Department of Conservation: Hamilton, New Zealand. 179 p.

Collier KJ, Allan M, Rowe D. 2015. Invasive fish community impacts. In New Zealand Invasive Fish Management Handbook, Collier KJ, Grainger NPJ (eds). Lake Ecosystem Restoration New Zealand (LERNZ; The University of Waikato) and Department of Conservation: Hamilton, New Zealand; 23-28.

Compton TJ, de Winton M, Leathwick JR, Wadhwa S. 2012. Predicting spread of invasive macrophytes in New Zealand lakes using indirect measures of human accessibility. Freshwater Biology 57: 938-948.

Copp GH, Vilizzi L, Gozlan RE 2010. The demography of introduction pathways, propagule pressure and occurrences of non-native freshwater fish in England. Aquatic Conservation: Marine and Freshwater Ecosystems 20: 595-601.

Copp GH, Vilizzi L, Mumford J, Fenwick GV, Godard MJ, Gozlan RE 2009. Calibration of FISK, an invasiveness screening tool for non-native freshwater fishes. Risk Analysis 29: 457-467.

Córdova-Tapia F, Contreras M, Zambrano L. 2015. Trophic niche overlap between native and nonnative fishes. Hydrobiologia 746: 291-301.

Drake DC, Kelly DJ, Schallenberg M. 2010. Shallow coastal lakes in New Zealand: current conditions, catchment-scale human disturbance, and determination of ecological integrity. Hydrobiologia 658: 87-101.

Dudgeon D, Arthington AH, Gessner MO, Kawabata Z-I, Knowler DJ, Leveque C, Naiman RJ, PrieurRichard AH, Soto D, Stiassny ML, Sullivan CA. 2006. Freshwater biodiversity: importance, threats, status and conservation challenges. Biological Reviews 81: 163-182.

Elith J, Leathwick R, Hastie T. 2008. A working guide to boosted regression trees. Journal of Animal Ecology 77: 802-813.

Friedman JH. 2001. Greedy function approximation: the gradient boosting machine. Annals of Statistics 29: 1189-1232.

Friedman JH. 2002. Stochastic gradient boosting. Computational Statistics and Data Analysis 38 : 367-378. 
Vulnerability of lakes to fish invasion impacts

Hanley JA, McNeil BJ. 1982. The meaning and use of the area under a receiver operating characteristic (ROC) curve. Radiology 143: 29-36.

Havel JE, Kovalenko KE, Thomaz SM, Amalfitano S, Kats LB. 2015. Aquatic invasive species: challenges for the future. Hydrobiologia 750: 147-170.

IPCC. 2005. Guidance notes for lead authors of the IPCC fourth Assessment Report on Addressing Uncertainties. Intergovernmental Panel on Climate Change. WMO \& UNEP. 4 p.

Johnson PTJ, Olden JD, Vander Zanden MJ. 2008. Dam invaders: impoundments facilitate biological invasions into freshwaters. Frontiers of Ecology Environment 6: 357-363.

Kizuka T, Akasaka M, Kadoya T, Takamura N. 2014. Visibility from roads predict the distribution of invasive fishes in agricultural ponds. PLoS ONE 9: e99709.

Kolar CS, Lodge DM. 2002. Ecological predictions and risk assessment for alien fishes in North America. Science 298: 1233-1236.

Latzka AW, Hansen GJA, Kornis M, Vander Zanden MJ. 2016. Spatial heterogeneity in invasive species impacts at the landscape scale. Ecosphere 7: e01311.

Leathwick JR, Collier KJ, Hicks BJ, Ling N, Stichbury G, de Winton M. in press. Predictions of establishment risk highlight biosurveillance priorities for invasive fish in New Zealand lakes. Freshwater Biology.

Leathwick JR, Elith J, Chadderton WL, Rowe R, Hastie T. 2008. Dispersal, disturbance and the contrasting biogeographies of New Zealand's diadromous and non-diadromous fish species. Journal of Biogeography 35: 1481-1497.

Leathwick JR, West D, Gerbeaux P, Kelly D, Robertson H, Brown D, Chadderton WL, Ausseil A-G. 2010. Freshwater ecosystems of New Zealand (FENZ) geodatabase user guide version 1. Department of Conservation, Wellington.

Leprieur F, Beauchard O, Blanchet S, Oberdorff T, Brosse S. 2008. Fish invasions in the world's river systems: when natural processes are blurred by human activities. PLoS Biol 6: e28.

Matsuzaki S-I, Takamura N, Arayama K, Tominaga A, Iwasaki J, Washitani I. 2011. Potential impacts of non-native channel catfish on commercially important species in a Japanese lake, as inferred from long-term monitoring data. Aquatic Conservation: Marine and Freshwater Ecosystems 21: 348-358.

McDowall RM. 2000. The Reed field guide to New Zealand freshwater fishes. Reed Publishing, Auckland, New Zealand. 224 p.

McDowall RM, Richardson J. 1983. The New Zealand freshwater fish survey, a guide to input and output. Fisheries Research Division Information Leaflet 12: 1-15. New Zealand Ministry of Agriculture and Fisheries, Wellington.

Mercado-Silva N, Olden JD, Maxted JT, Hrabik TR, Vander Zanden MJ. 2006. Forecasting the spread of invasive rainbow smelt in the Laurentian Great Lakes region of North America. Conservation Biology 20: 1740-1749. 
Vulnerability of lakes to fish invasion impacts

Moilanen A, Franco AMA, Early R, Fox R, Wintle B, Thomas CD. 2005. Prioritising multiple use landscapes for conservation: methods for large multi species planning problems. Proceedings of the Royal Society B 272: 1885-1891.

Moilanen A, Wilson KA, Possingham HP. 2009. Spatial conservation prioritization: Quantitative methods and computational tools. Oxford University Press, Oxford.

Morgan DL, Hambleton SJ, Gill HS, Beatty SJ. 2002. Distribution, biology and likely impacts of the introduced redfin perch (Perca fluviatilis) in Western Australia. Marine and Freshwater Research 53: 1211-1221.

Papes M, Sällström M, Asplund TR, Vander Zanden MJ. 2011. Invasive species research to meet the needs of resource management and planning. Conservation Biology 25: 867-872.

Rahel FJ, Olden JD. 2008. Assessing the effects of climate change on aquatic invasive species. Conservation Biology 22: 521-533.

Ridgeway G. 2015. Package 'gbm'. Version 2.1. http://cran.rproject.org/web/packages/gbm/index.html

Rooney TP, Olden JD, Leach MK, Rogers DA. 2007. Biotic homogenization and conservation prioritization. Biological Conservation 134: 447-450

Rowe DK. 2007. Exotic fish introductions and the decline of water clarity in small North Island, New Zealand lakes: a multi-species problem. Hydrobiologia 583: 345-358.

Rowe DK, Wilding T. 2012. Risk assessment model for the introduction of non-native freshwater fish into New Zealand. Journal of Applied Ichthyology 28: 582-589.

Schallenberg M, Sorrell B. 2009. Regime shifts between clear and turbid water in New Zealand lakes: environmental correlates and implications for management and restoration. New Zealand Journal of Marine and Freshwater Research 43: 701-712

Smith KF, Lester PJ. 2007. Trophic interactions promote dominance by cyanobacteria (Anabaena spp.) in the pelagic zone of Lower Karori Reservoir, Wellington, New Zealand. New Zealand Journal of Marine and Freshwater Research 41: 143-155.

Snelder T. 2006. Definition of a multivariate classification of New Zealand lakes. NIWA Client Report: CHC2006-084. National Institute of Water and Atmospheric Research, Christchurch.

Strayer DL. 2010. Alien species in freshwaters: ecological effects, interactions with other stressors, and prospects for the future. Freshwater Biology 55: 152-174.

Tricarico E. 2016. Do alien invasive species and climate change foster conservation behaviour. Aquatic Conservation: Marine and Freshwater Ecosystems 26: 228-232.

Van der Veer G, Nentwig W. 2015. Environmental and economic impact assessment of alien invasive fish species in Europe using the generic impact scoring system. Ecology of Freshwater Fish 24: 646-656.

Vander Zanden MJ, Olden JD. 2008. A management framework for preventing the secondary spread of aquatic invasive species. Canadian Journal of Fisheries and Aquatic Sciences 65: 1512-1522.

Vander Zanden MJ, Olden JD, Thorne JH, Mandrak ME. 2004. Predicting occurrences and impacts of bass introductions in north temperate lakes. Ecological Applications 14: 132-148. 
Vulnerability of lakes to fish invasion impacts

Villéger S, Grenouillet G, Suc V, Brosse S. 2012. Intra- and interspecific differences in nutrient recycling by European freshwater fish. Freshwater Biology 57: 2330-2341.

Walsh JR, Carpenter SR, Vander Zanden MJ. 2016. Invasive species triggers a massive loss of ecosystem services through a trophic cascade. PNAS 113: 4081-4085. 
Vulnerability of lakes to fish invasion impacts

Table 1. Performance of best predictive models (increase in Area Under Curve (AUC) > 0.005) for the distribution of seven invasive fish species in New Zealand lakes using (i) environmental and human population based models $(*)$, or (ii) environmental, human and catchment presence based models $\left({ }^{* *}\right)$. Median probability of establishment is derived from predictions of fish species across New Zealand lakes $>1$ ha $(n=3,595)$.

Model performance

\begin{tabular}{lcccc}
\cline { 2 - 4 } & $\begin{array}{c}\text { Total } \\
\text { deviance }\end{array}$ & $\begin{array}{c}\text { Residual } \\
\text { deviance }\end{array}$ & AUC & $\begin{array}{c}\text { Median } \\
\text { probability of } \\
\text { establishment }\end{array}$ \\
\hline Catfish** & 0.847 & 0.408 & 0.947 & 0.301 \\
Gambusia** & 0.938 & 0.511 & 0.935 & 0.004 \\
Goldfish* & 1.361 & 0.906 & 0.873 & 0.044 \\
Common carp** & 0.454 & 0.318 & 0.872 & 0.009 \\
Perch** & 1.101 & 0.717 & 0.889 & 0.333 \\
Rudd* & 0.976 & 0.664 & 0.894 & 0.136 \\
Tench** & 0.569 & 0.395 & 0.878 & 0.005 \\
\hline
\end{tabular}

Table 2. Median and $5^{\text {th }}-95^{\text {th }}$ percentile values for invasion risk impact $(I R I)$ and lake vulnerability $(L V)$ scores integrating ecological impact and conservation rank for 3,431 New Zealand lakes with extents $>1$ ha.

\begin{tabular}{lccc}
\hline \multicolumn{1}{c}{ A. Species-specific $\mathbf{I R I}$ score } & $\mathbf{5}^{\text {th }}$-percentile & Median & $\mathbf{9 5}^{\text {th }}$-percentile \\
Catfish & 0.131 & 0.317 & \\
Gambusia & 0.001 & 0.004 & 0.665 \\
Goldfish & 0.018 & 0.047 & 0.179 \\
Common carp & 0.010 & 0.012 & 0.508 \\
Perch & 0.160 & 0.363 & 0.083 \\
Rudd & 0.087 & 0.151 & 0.755 \\
Tench & 0.001 & 0.005 & 0.080 \\
IRI (all species) & 0.142 & 0.202 & 0.405 \\
$\quad$ B. Species-specific $\boldsymbol{L V}$ score & & \\
Catfish & 0.019 & 0.158 & 0.369 \\
Gambusia & 0.000 & 0.002 & 0.060 \\
Goldfish & 0.005 & 0.020 & 0.209 \\
Common carp & 0.001 & 0.008 & 0.040 \\
Perch & 0.023 & 0.181 & 0.540 \\
Rudd & 0.011 & 0.081 & 0.259 \\
Tench & 0.000 & 0.003 & 0.023 \\
LV (all species) & 0.017 & 0.111 & 0.258 \\
\hline
\end{tabular}


Vulnerability of lakes to fish invasion impacts

Table 3. Species-specific and total Lake Vulnerability (LV) scores, along with conservation rank and Invasion risk impact (IRI) for three case study areas with different lake types in the North Island (N.I.) and South Island (S.I.) of New Zealand.

\begin{tabular}{|c|c|c|c|c|c|c|c|c|c|}
\hline \multirow[b]{2}{*}{ Name } & \multicolumn{3}{|c|}{ Coastal dune lakes (N.I.) } & \multicolumn{3}{|c|}{ Shallow riverine lakes (N.I.) } & \multicolumn{3}{|c|}{ Deep large lakes (S.I.) } \\
\hline & Humuhumu & Mokeno & Kanono & Waikare & Whangape & Waahi & Wakatipu & Te Anau & Manapouri \\
\hline Catfish & 0.33 & 0.26 & 0.09 & 0.77 & 0.71 & 0.78 & 0.22 & 0.21 & 0.24 \\
\hline Gambusia & 0.48 & 0.09 & 0.08 & 0.88 & 0.66 & 0.80 & 0.00 & 0.00 & 0.00 \\
\hline Goldfish & 0.15 & 0.19 & 0.04 & 0.84 & 0.69 & 0.75 & 0.02 & 0.02 & 0.01 \\
\hline Common carp & 0.06 & 0.06 & 0.01 & 0.85 & 0.72 & 0.66 & 0.01 & 0.01 & 0.01 \\
\hline Perch & 0.70 & 0.74 & 0.15 & 0.37 & 0.31 & 0.42 & 0.22 & 0.19 & 0.14 \\
\hline Rudd & 0.60 & 0.33 & 0.14 & 0.21 & 0.59 & 0.71 & 0.14 & 0.13 & 0.09 \\
\hline Tench & 0.01 & 0.01 & 0.06 & 0.05 & 0.03 & 0.06 & 0.01 & 0.00 & 0.00 \\
\hline Conservation rank & 200 & 524 & 2,568 & 408 & 967 & 676 & 1,034 & 1,155 & 2,216 \\
\hline IRI (all species) & 0.51 & 0.40 & 0.46 & 0.88 & 0.99 & 1.00 & 0.18 & 0.17 & 0.29 \\
\hline LV (all species) & 0.52 & 0.37 & 0.13 & 0.88 & 0.82 & 0.90 & 0.14 & 0.12 & 0.11 \\
\hline
\end{tabular}


Vulnerability of lakes to fish invasion impacts

FIGURE CAPTIONS

Figure 1. New Zealand's North and South Island lakes showing predicted $(A)$ invasion risk impact and (B) lake vulnerability to loss of conservation value from seven invasive fish species assuming presence in the catchment.

Figure 2. Relationships between invasion risk impact and relative conservation rank (higher values indicate higher ranking sites) for 3,431 lakes $>1$ ha throughout New Zealand showing (A) number of species per lake (range 1-6 for smallest to largest circles) and (B-H) individual species occurrence per lake from available records (black symbols) compared to predictions for all New Zealand lakes for which no data exist (grey symbols).

Figure 3. New Zealand's North and South islands showing predicted lake vulnerability to impacts from invasion by (A) catfish and (B) perch assuming presence in the catchment.

Figure 4. Framework for identifying priority sites for surveillance and monitoring of potential invasive fish incursion. The pale grey shaded rectangle highlights lakes of moderate-to-high conservation rank and a moderate probability of adverse environmental impacts from invasive fish, and grey circles within this area highlight lakes for which no records exist or where invasive fish are absent and that might be considered priorities for surveillance; black circles indicate lakes where invasive fish species have been reported. 
Vulnerability of lakes to fish invasion impacts

1

2

3

4

5

6

7

8

9

10

11

12

13

14

15

16

17

18

19

20

21

22

23

24

25

26

27

28

29

30

31

32

33

34

35

36

37

38

39

40

41

42

43

44

45

46

47

48

49

50

51

52

53

54

55

56

57

58

59

60 

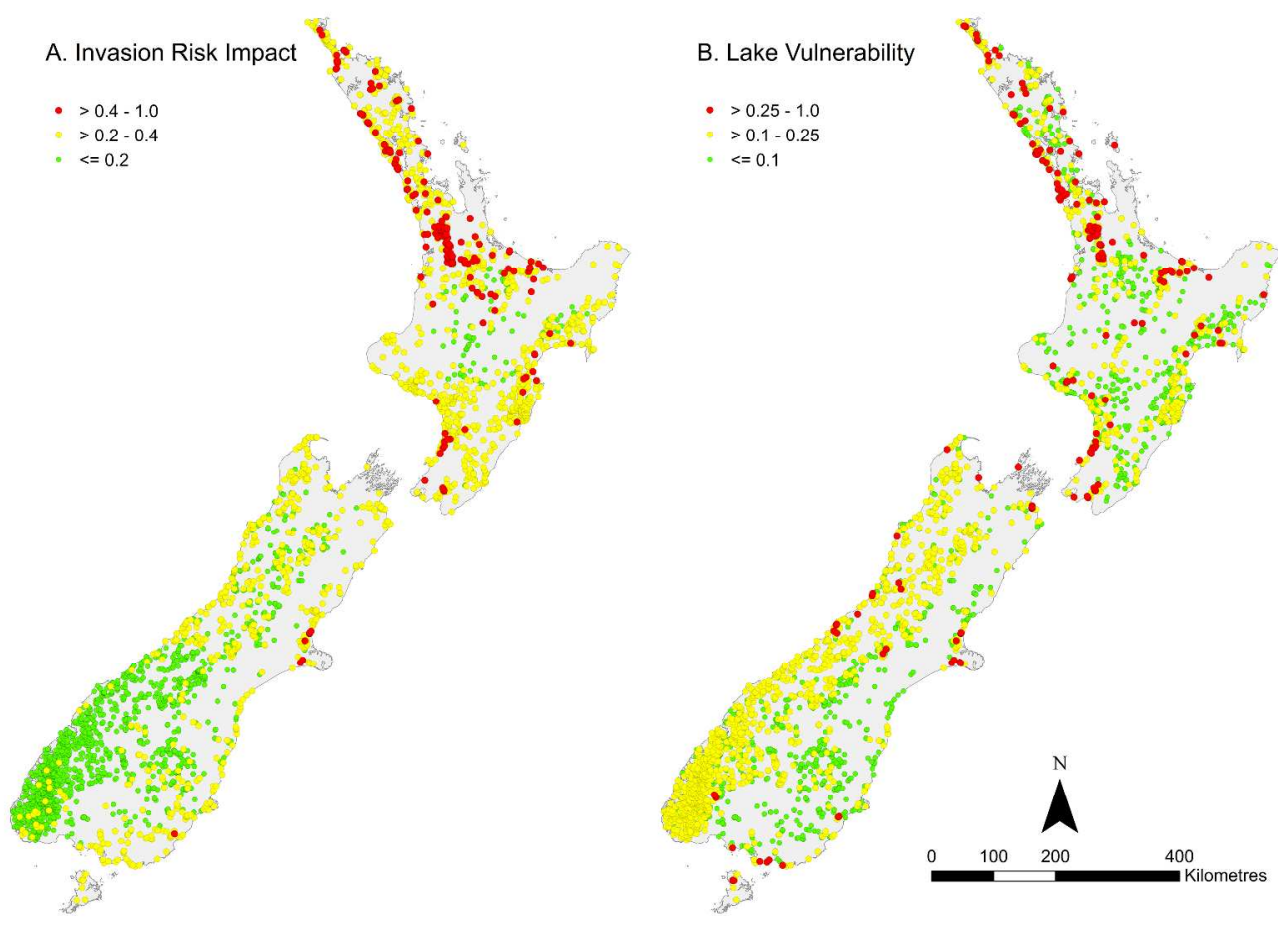

New Zealand's North and South Island lakes showing predicted (A) invasion risk impact and (B) lake vulnerability to loss of conservation value from seven invasive fish species assuming presence in the catchment. $1058 \times 747 \mathrm{~mm}(96 \times 96$ DPI) 


\section{A. Number of species}

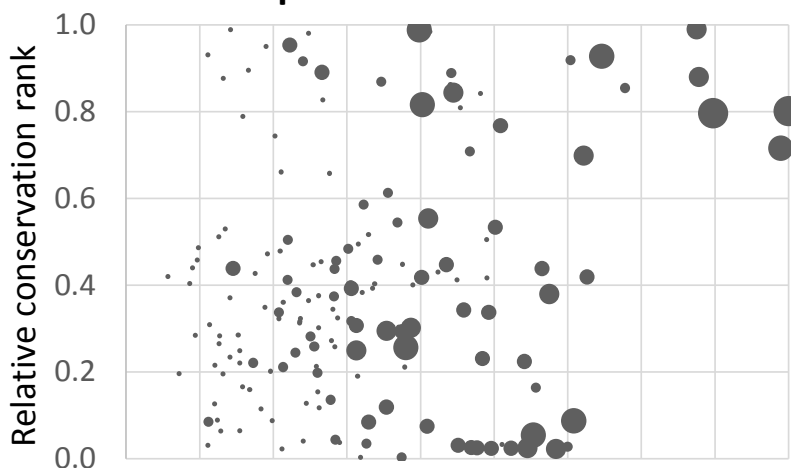

C. Goldfish

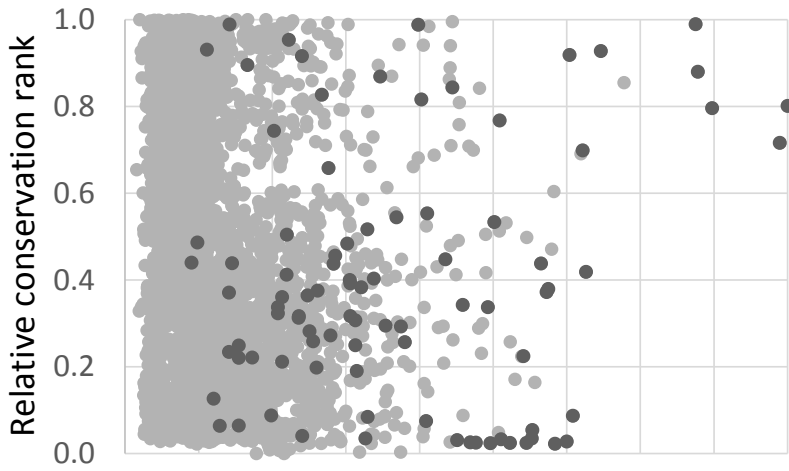

\section{E. Gambusia}

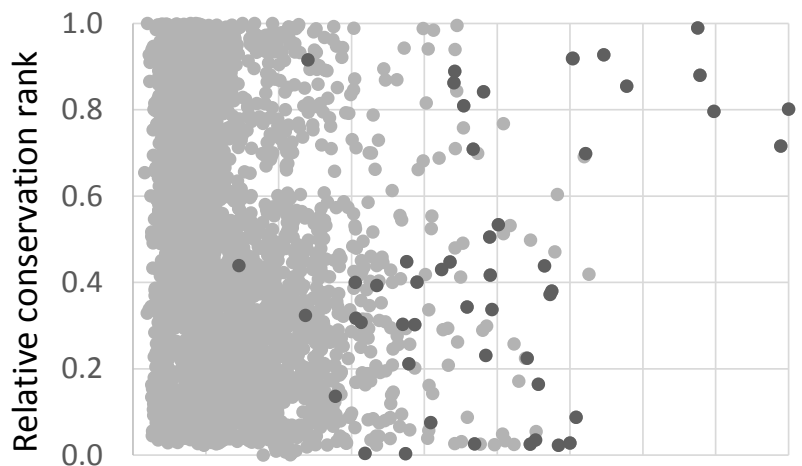

\section{G. Rudd}

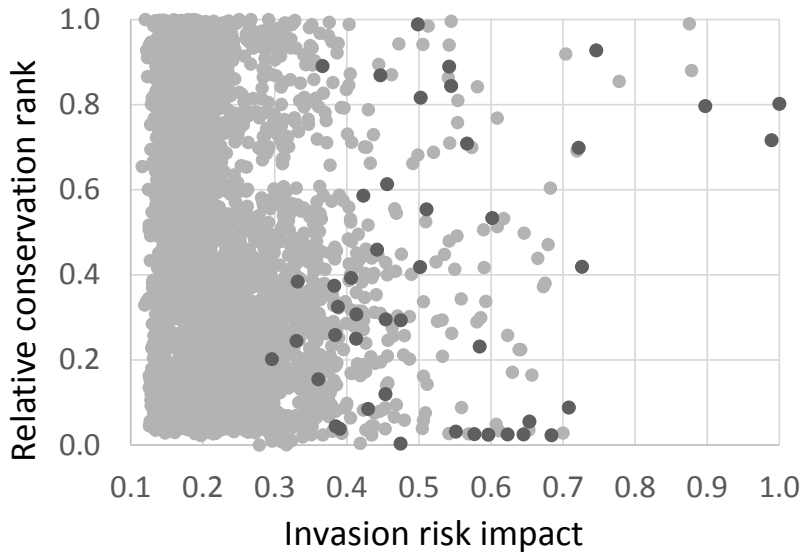

B. Catfish

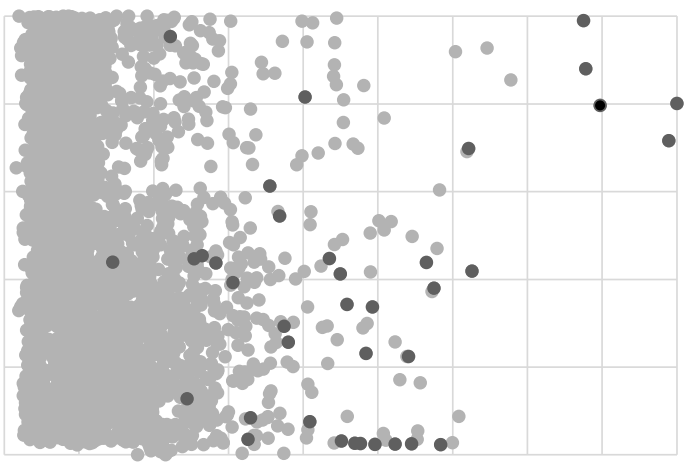

D. Koi carp

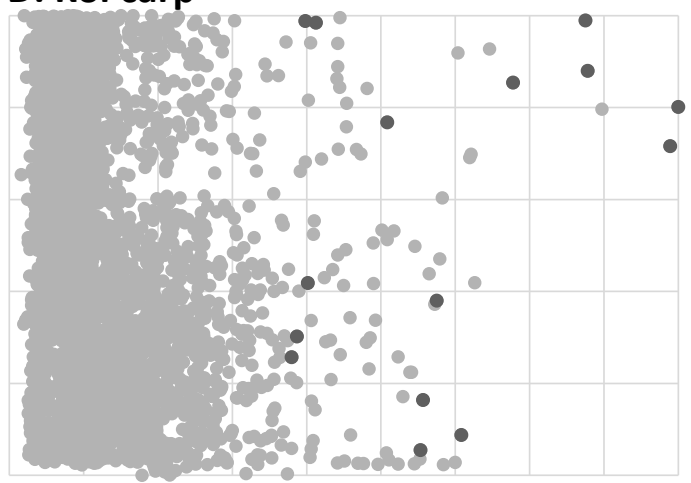

\section{F. Perch}

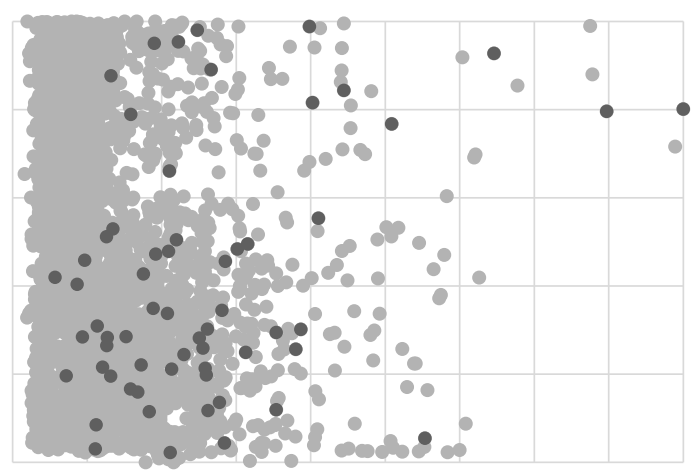

\section{H. Tench}

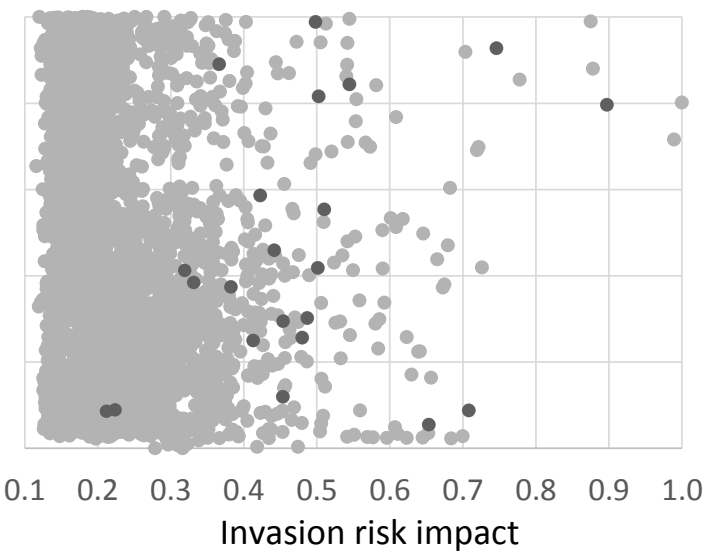



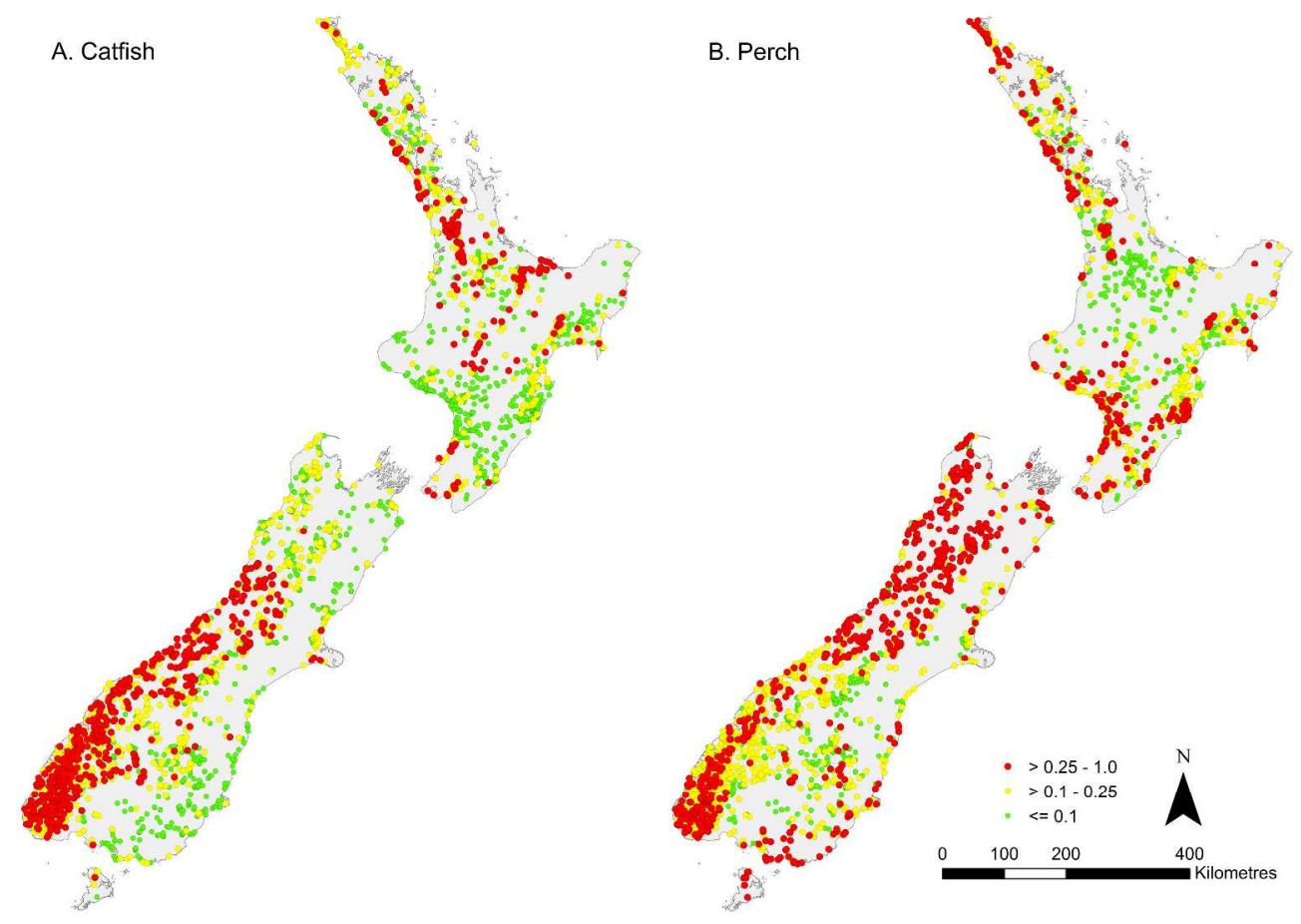

New Zealand's North and South islands showing predicted lake vulnerability to impacts from invasion by $(A)$ catfish and (B) perch assuming presence in the catchment. $1058 \times 747 \mathrm{~mm}(96 \times 96 \mathrm{DPI})$ 


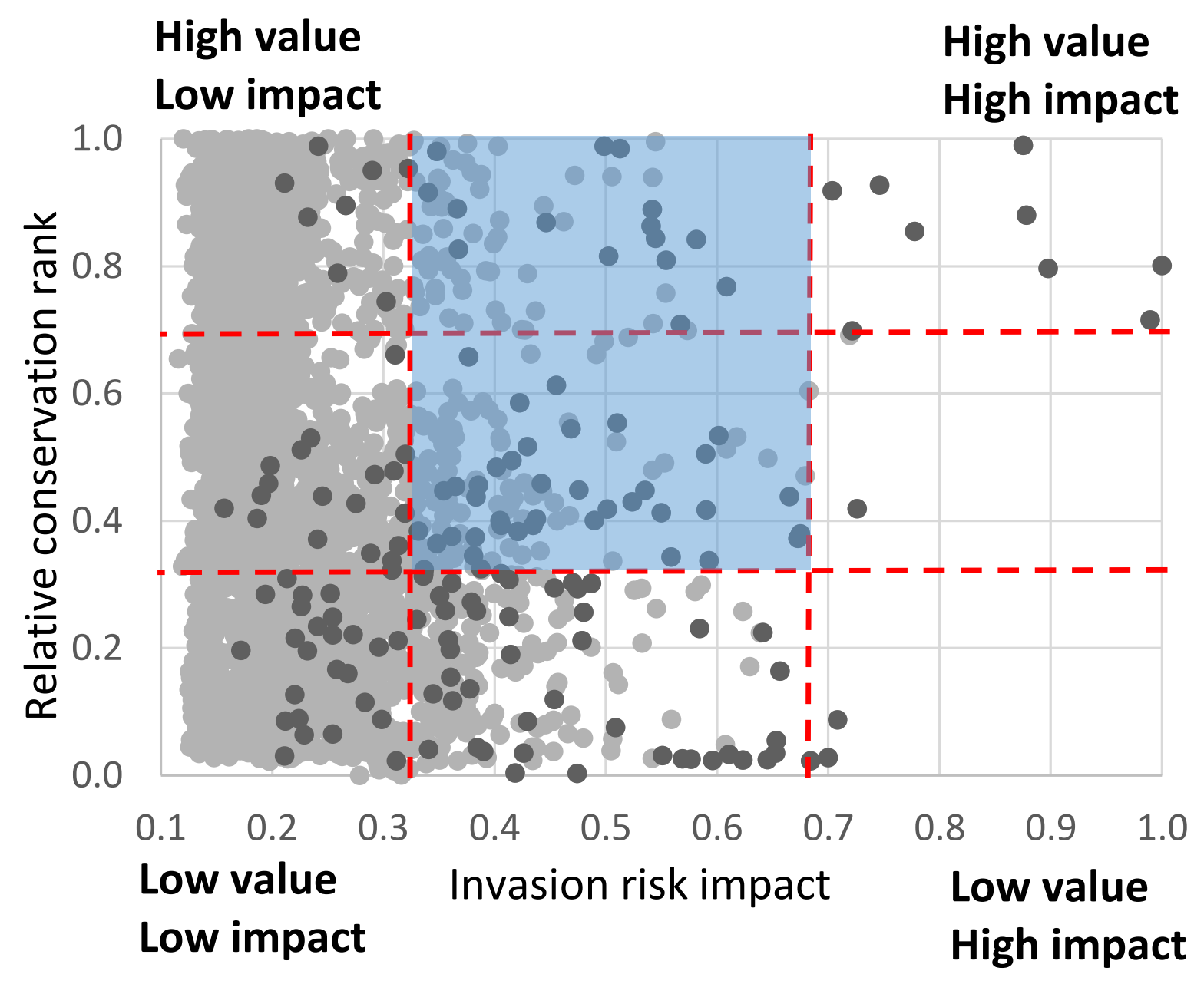

